\title{
The Blood-Retinal Barrier: Leucine Transport by the Retinal Pigment Epithelium
}

\author{
P. A. Sellner \\ Neurosurgical Service, Massachusetts General Hospital, Boston, Massachusetts 02114
}

The transport of leucine across the isolated bullfrog pigment epithelium-choroid was studied in a modified Ussing chamber. With the same concentration of leucine on both sides of the tissue, there was a net flux in the apical-to-basal (retina-tochoroid) direction. The concentration dependence of the apicalto-basal flux comprised at least 2 components: a carrier-mediated flux, with an apparent $K_{\mathrm{m}}$ of $0.76 \mathrm{~mm}$ and a $V_{\max }$ of 298 $\mathrm{nmol} / \mathrm{cm}^{2} / \mathrm{hr}$, and a linear component with a slope of $33.4 \mathrm{~cm} /$ hr. The basal-to-apical flux was linear to $10 \mathrm{~mm}$ leucine, with a slope of $60 \mathrm{~cm} / \mathrm{hr}$. In the absence of $\mathrm{Na}^{+}$, the apical-to-basal flux was inhibited $20 \%$, while the basal-to-apical flux was unaffected. The apical-to-basal flux could be inhibited to the level of the basal-to-apical flux by removing glucose from the solution and adding $\mathrm{KCN}$. Otherwise both fluxes were relatively unaltered by metabolic poisons.

There appear to be 3 contributors to the apical-to-basal flux: a weakly $\mathrm{Na}^{+}-$dependent carrier, a linear component (diffusion), and a countertransport mechanism. The basal-to-apical flux must have 2 linear mechanisms, diffusion to the same extent as the opposite flux, and possibly pinocytosis.

The blood--brain and blood-retinal barriers (the blood-CNS barriers) control the environment surrounding the neurons. They protect the extracellular fluid by preventing the entry of foreign substances such as large-molecular-weight proteins or certain organic solutes. The blood-CNS barriers comprise (1) the set of cerebral or retinal capillaries and (2) the choroid plexus, or choroid, consisting of a layer of epithelium and a capillary bed. The endothelial cells of neural capillaries are sealed with tight junctions that prevent bulk fluid movement. The plasma membranes of these endothelial cells, however, possess ion and solute transport systems (e.g., amino acid carriers), which regulate the flux of these molecules from the blood into the extracellular fluid and vice versa. In the retina, this type of capillary, if present, nourishes at most the inner retina, as these vessels never penetrate the photoreceptor layer.

The blood supply to avascular retinas and to the distal half of all retinas is provided by the vessels of the choroid, which lines the inside of the eye just as the choroid plexus lines a cerebral ventricle. The endothelial cells of these vessels are not sealed, creating fenestrations in the capillaries. The basement membrane separating these "leaky" capillaries from the adjacent epithelial cell layer likewise exerts no selectivity on the

\footnotetext{
Received July 2, 1985; revised Mar. 17, 1986; accepted Apr. 17, 1986.

The author wishes to thank Dr. Richard Masland in whose laboratory these experiments were performed. His support, encouragement, and insightful suggestions contributed greatly to this work, and are very much appreciated. I am also indebted to Dr. Terry Reedy for the use of his computer program "DIFFIT" for flux analysis. This study was supported by NIH Postdoctoral Fellowship EY05580 (P.A.S.) and by NIH Grant EY01075 to Dr. Masland.

Correspondence should be addressed to Dr. Peggy A. Sellner, Department of Ophthalmology, University of Kansas Medical Center, Kansas City, KS 66103, the author's present address.

Copyright (c) 1986 Society for Neuroscience $0270-6474 / 86 / 102823-06 \$ 02.00 / 0$
}

passage of solutes. The epithelial cells, in contrast, possess several features consistent with other selectively transporting epithelia. First, in both the choroid plexus and retinal pigment epithelium (RPE), the basolateral membranes of these cells have numerous infoldings, increasing the surface area available for exchange with the plasma ultrafiltrate. Second, the cells are joined near the apical ends with junctional complexes (i.e., structures that include tight junctions), which form a tight intercellular seal. Third, the apical membrane is characterized by long, villous-like processes and (in the RPE) a $\mathrm{Na}^{+}-\mathrm{K}^{+}$-ATPase is localized to this border (Bok, 1982; Ostwald and Steinberg, 1980). The epithelial cell layer is thus designed to modify the plasma ultrafiltrate in the process of fluid secretion. Cerebrospinal fluid is not simply an ultrafiltrate of plasma, as ion and solute concentrations in the 2 fluids differ as much as 10-fold (Altman and Dittmer, 1974). Clearly, the choroid plexus and RPE-choroid play an important part in detcrmining the cxtracellular environment around the brain and retina, respectively.

Ion and solute movement across these barriers occurs by diffusion, by a specialized transport system, or by pinocytosis. One consequence of this arrangement is the problem of maintaining a constant rate of solute movement in the face of fluctuating solute levels in the blood. That is, how does the blood-CNS barrier control the secretion of solute? Transport properties of the choroid plexus have been studied (Lorenzo, 1974), but the preparation is difficult because of its relative inaccessibility. In contrast, the RPE-choroid is easily isolated and placed in an Ussing chamber, enabling the experimenter to control the composition of the fluid on both sides. Using such a preparation, Miller and Steinberg (1976) found that the amino acids taurine and methionine exhibited a net flux from the retina toward the blood side of the tissue in the absence of a concentration gradient. That is, the RPE is designed to clear amino acids from the subretinal fluid. A net flux away from the retina was observed for several other amino acids (Sellner, in press), with the apicalto-basal flux 2-8 times the basal-to-apical flux.

In this report, the transport of a particular amino acid, leucine, was investigated to clarify the mechanism(s) responsible for the net apical-to-basal movement, and to help understand the role of the RPE in supplying membrane precursors to the photoreceptors. While the analysis is complicated by the presence of 2 membranes through which the substrate must pass, some conclusions can be drawn about the relative contributions of carriermediated transport, diffusion, and other systems.

\section{Materials and Methods}

\section{Dissection}

The procedure for preparation of the isolated RPE-choroid has been described by Miller and Steinberg (1977) and Lasansky and deFisch (1966). In brief, male bullfrogs (5-6 in. Rana catesbeiana, obtained from Connecticut Valley or West Jersey Biological Supply) were chilled in ice water and dark-adapted for at least $2 \mathrm{hr}$ prior to sacrifice. Under dim red light, the animals were double-pithed and the eyes enucleated 


\begin{tabular}{lcccc}
$\begin{array}{l}\text { Table 1. } \\
\text { leucine }\end{array}$ & Unidirectional clearances of extracellular markers and \\
Substrate & $\begin{array}{l}\text { Conc. } \\
(\mathrm{mM})\end{array}$ & Apical $\rightarrow$ basal & Basal $\rightarrow$ apical & Ratio \\
\hline Inulin & 2 & $4.4 \pm 0.7$ & $4.65 \pm 0.85$ & 0.9 \\
& & $(5)$ & $(5)$ & \\
Mannitol & 2 & $6.0 \pm 1.25$ & $5.35 \pm 1.45$ & 1.1 \\
& & $(8)$ & $(9)$ & \\
Mannitol & 1 & 3.5 & 3.3 & \\
& & 6.4 & 21.2 & \\
Lcucinc & 1 & 203.8 & 80.9 & \\
& & 236.4 & 92.8 &
\end{tabular}

Clearances are microliters $/ \mathrm{cm}^{2} / \mathrm{hr}$; data are expressed as means \pm SD for the number of experiments given in parentheses, or as the results of individual experiments.

and hemisected. The posterior half of each eye was then hemisected, yielding 4 pieces which were immediately immersed in a high-bicarbonate saline solution (Miller and Steinberg, 1977) equilibrated with $\mathrm{O}_{2} / \mathrm{CO}_{2}(95: 5)$. Two pairs of fine-tipped forceps were used to carefully peel off the retina. At this point, white lights were turned on and the quarters were transferred to fresh solution that was constantly gassed with $\mathrm{O}_{2} / \mathrm{CO}_{2}$. A piece of tissue (RPE-choroid) was prepared for flux experiments by trimming it to a square, $5-6 \mathrm{~mm}$ per side. The RPEchoroid was then carefully peeled off from 2 diagonally opposite corners, bringing the edges of the tissue toward the center.

The tissue square was slipped onto a piece of $\mathrm{x}$-ray film or nylon mesh (Tetko, Inc.) that had been coated with a $21.5 \%$ solution of BSA, $\mathrm{pH} \mathrm{7,} \mathrm{using} \mathrm{a} \mathrm{cotton-tipped} \mathrm{swab.} \mathrm{The} \mathrm{film} \mathrm{or} \mathrm{mesh} \mathrm{was} \mathrm{sandwiched}$ between 2 lucite plates, as described previously (Miller and Steinberg, 1977), and the plates were screwed together tightly enough to seal the edge of the tissue. The plates plus tissue were placed in a modified Ussing chamber such that the assembly divided the chamber into 2 compartments of approximately $2.0 \mathrm{ml}$ each. Each compartment was filled with solution and gassed with $\mathrm{O}_{2} / \mathrm{CO}_{2}$ through 30-gauge hypodermic needles inserted into gassing sleeves of fine tubing.

One pair of agar bridges was used to measure the transepithelial potential across the tissue. A second pair was used to determine the transepithelial resistance by passing a small DC pulse (approximately $2.7 \mu \mathrm{A}$ ) across the tissue and observing the change in potential. Miller and Steinberg (1977) have indicated that a properly prepared tissue has a potential of $10-15 \mathrm{mV}$ and a resistance of at least $300 \Omega \mathrm{cm}^{2}$. While we were able, after some practice, to observe potentials of that magnitude (mean $\pm \mathrm{SD}=10.5 \pm 2.6 \mathrm{mV}, n=402$ tissues), we were unable to achieve such high resistances on a routine basis (mean $\pm \mathrm{SD}=210 \pm$ $30 \Omega \mathrm{cm}^{2}$ ). However, we believe our results to be reliable for the following reasons: First, after the initial period of familiarization with the dissection and preparation, the potentials and resistances were very consistent. Second, the fluxes with inulin and mannitol showed no evidence of a gross leak across the tissue, even with these lower resistances (see below). Modifying the lucite plates and using nylon mesh instead of the $x$-ray film resulted in more stable parameters over time, but an increase in the resistances was not observed. Finally, there was no correlation between the variability in fiux measurements and the variability in electrical parameters. We have no explanation for the difference in magnitude of the parameters of our preparations from those of Miller and Steinberg. One possibility lies in their use of voltage-clamped preparations while these experiments were performed under open-circuit conditions. Another possibility is that the resistance was limited by the effectiveness of the seal between the 2 lucite plates, which, in turn, was limited by the physical distance between these machined parts.

\section{Flux measurements}

For single-label flux measurements, the solution in each compartment was replaced by the solution containing the substrate at a given concentration. To one side of the chamber a trace amount of ${ }^{3} \mathrm{H}$-substrate (New England Nuclear) was added. The specific activity of this side was determined by counting a $25 \mu \mathrm{l}$ aliquot. Samples of $100 \mu \mathrm{l}$ were removed from the opposite side at various intervals and replaced by aliquots of

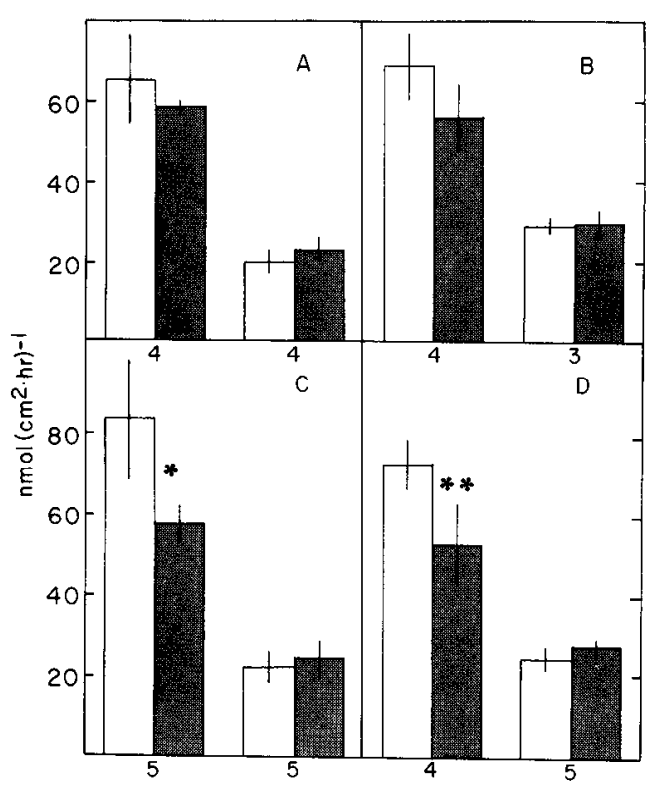

Figure 1. Effect of altering the sodium gradient on leucine transport across the retinal pigment epithelium (RPE). Unidirectional fluxes of leucine $(250 \mu \mathrm{M})$ were measured as described in Materials and Methods. The 2 bars on the left in each panel represent the apical-to-basal flux, and the 2 bars on the right in each panel the basal-to-apical flux. Fluxes measured in control solution are indicated by open bars; those in the test solution by shaded bars. Data are shown as means \pm SD for the number of tissues indicated. $A, \mathrm{NaCl}$ in control solution (75\% of total $\mathrm{Na}^{+}$) replaced by $\mathrm{LiCl} . B, \mathrm{NaCl}$ replaced with choline chloride. $C$, HEPES substituted for $\mathrm{NaHCO}_{3}$ and choline chloride for $\mathrm{NaCl}$. The $\mathrm{pH}$ was adjusted with Tris- $\mathrm{HCl}(20 \mu \mathrm{M}) .{ }^{*} p<0.001 . D$, Ouabain added to both sides of the chamber to a final concentration of $10^{-4} \mathrm{M} .^{* *} p<$ 0.05 .

solution containing unlabeled substrate. During these experiments, 2 tissues were usually run in parallel, one to measure the apical-to-basal flux, the other to measure the basal-to-apical flux. Experiments were performed in normal (white) room light at room temperature and under open-circuit conditions unless otherwise indicated.

\section{Results}

\section{Measurement of unidirectional fluxes}

Inulin and mannitol fluxes were measured to verify the integrity of the preparation. For either substrate, the fluxes were equal in the apical-to-basal and basal-to-apical directions, and were quite small. To allow comparison with other substrates, fluxes were converted to clearance rates by dividing the nanomoles/ $\mathrm{cm}^{2} / \mathrm{hr}$ by the concentration of substrate, yielding microliters/ $\mathrm{cm}^{2} / \mathrm{hr}$ (Table 1). In these (comparable) units, mannitol fluxes constituted less than $5 \%$ of the leucine fluxcs. In cxperiments where mannitol and leucine were present in equal concentrations ( $1 \mathrm{~mm})$, the "leak" of the extracellular marker was very small relative to the amino acid (Table 1).

At a leucine concentration of $1 \mathrm{~mm}$, the clearance in the apicalto-basal direction was 2.5-3 times that in the opposite direction (Table 1). This net movement of the amino acid in the retinato-choroid direction has been observed for a variety of amino acids (Sellner, in press). The mechanism of leucine transport was investigated with respect to $\mathrm{Na}^{+}$dependence, saturability, and susceptibility to metabolic inhibitors.

\section{Mechanism of leucine transport}

In contrast to the A system for neutral amino acids (Oxender and Christensen, 1963), leucine transport across the RPE-cho- 


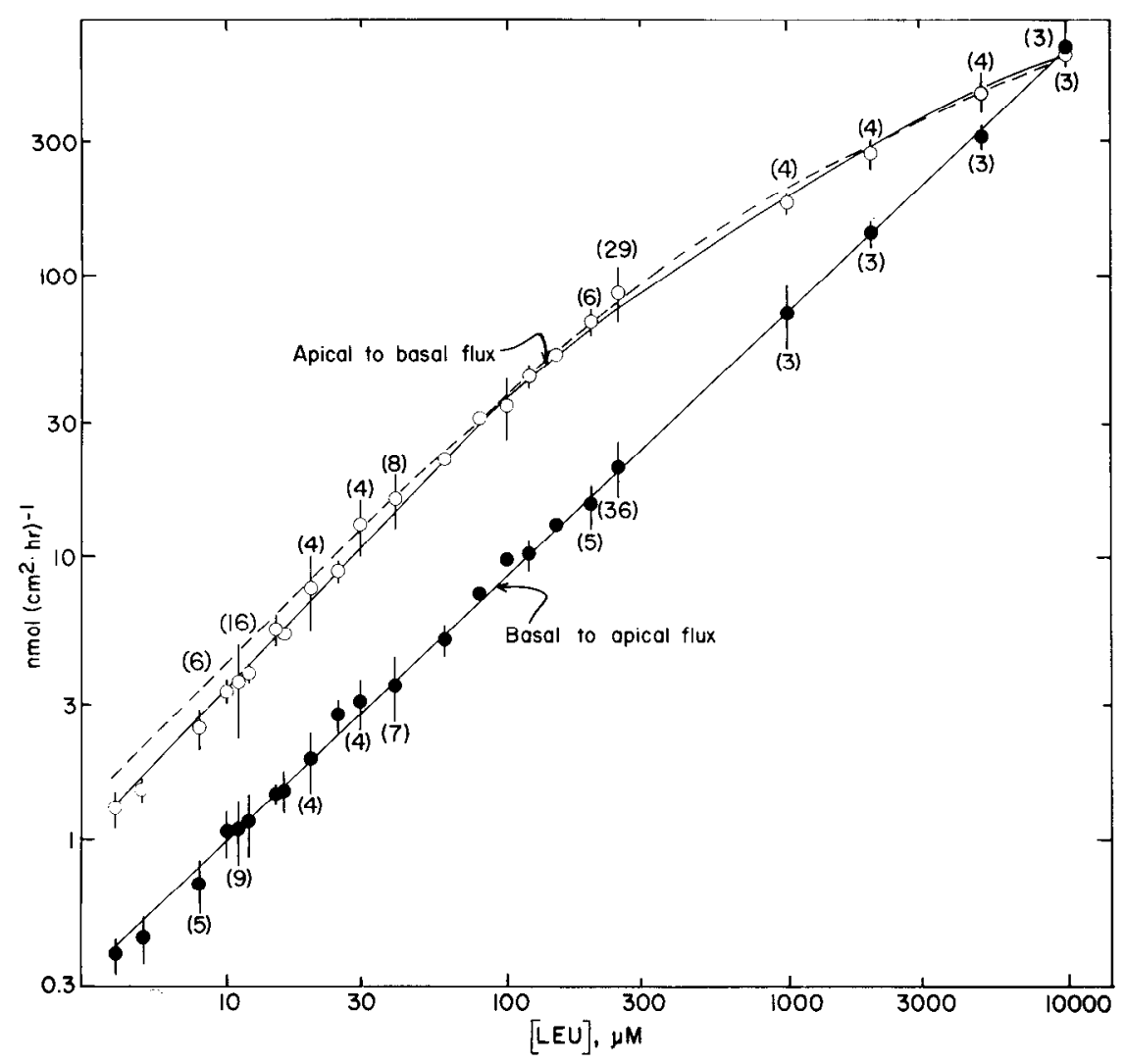

Figure 2. Unidirectional fluxes of leucine as a function of leucine concentration. Open circles, Apical-tobasal flux; filled circles, basal-to-apical flux. Data expressed in nanomoles $(\mathrm{nmol}) / \mathrm{cm}^{2} / \mathrm{hr}$ for the average and range of 2 measurements or, where indicated, as means \pm SD for the number of measurements (parentheses). In some cases, the range bar is smaller than the symbol and is therefore not shown. Dashed line. Best fit to the data, assuming a saturable, carrier-mediated component $\left(K_{\mathrm{m}}=0.76\right.$ $\left.\mathrm{mM}, V_{\max }=298 \mathrm{nmol} / \mathrm{cm}^{2} / \mathrm{hr}\right)$, and a a linear component (slope $=33.4 \mathrm{~cm} /$ $\mathrm{hr}$ ).

roid was only weakly $\mathrm{Na}^{+}$-dependent. For example, when $75 \%$ of the $\mathrm{Na}^{\prime}$ in the solution was replaced by $\mathrm{Li}^{+}$or choline, no change was observed in the apical-to-basal flux relative to control solution (Fig. 1, $A, B$ ). When $100 \%$ of the $\mathrm{Na}^{+}$was replaced with choline and HEPES, using Tris base (approximately $20 \mu \mathrm{M}$ ) to adjust $\mathrm{pH}$, there was a $20 \%$ decrease in the apical-to-basal flux (Fig. 1C). We also observed small decreases of the same magnitude with ouabain at a final concentration of $10^{-4} \mathrm{M}$ (Fig. $1 D$ ), with the $\mathrm{Na}^{+}$ionophore gramicidin, and with zero $\mathrm{K}^{+}$(data not shown). However, in none of these experiments was the apical-to-basal flux reduced to the level of the basal-to-apical flux. The latter was completely independent of changes in $\mathrm{Na}^{+}$ levels.

To determine whether either flux was due to a membraneassociated carrier, we looked for evidence of saturability with increasing leucine concentration. As shown in Figure 2, for up to $10 \mathrm{~mm}$ leucine the basal-to-apical flux was linear, with a slope of $60 \mathrm{~cm} / \mathrm{hr}$, consistent with free diffusion or no saturable carrier. Neither did the apical-to-basal flux saturate by $10 \mathrm{~mm}$ leucine, but it appeared to comprise saturable and nonsaturable components (Fig. 2). The data were fitted by an iteration program (the dashed line in Fig. 2) to a model that included a carrier-mediated (Michaelis-Menten) term and a linear component. The apparent $K_{\mathrm{m}}$ was $0.76 \mathrm{mM}$, with a $V_{\max }$ of $298 \mathrm{nmol} /$ $\mathrm{cm}^{2} / \mathrm{hr}$. The linear component had a slope of $33.4 \mathrm{~cm} / \mathrm{hr}$. Note that the fit to the experimental data is best at high concentrations and is less accurate in the low-concentration range.

When the data were expressed as clearance rates (Fig. 3), the basal-to-apical movement of the substrate showed a small decline over the $10 \mathrm{~mm}$ concentration range. The apical-to-basal clearance increased in the 10-30 $\mu \mathrm{M}$ range, was relatively constant between 60 and $250 \mu \mathrm{M}$, and then decreased sharply with millimolar levels of substrate. This suggests that the flux in the apical-to-basal direction is sensitive to its osmotic environment, while the basal-to-apical flux is not.

The fluxes in the 2 directions were not found to be stereo- specific, that is, adding D-leucine to L-leucine yielded clearances that were not different from those expected if all the leucine present were in the $\mathrm{L}$ form (Table 2 ).

The basal-to-apical flux appeared completely resistant to a variety of metabolic inhibitors, while the apical-to-basal flux showed a more variable response. For example, there was little or no change in the apical-to-basal flux of $250 \mu \mathrm{M}$ leucine in the presence of dinitrophenol $\left(10^{-4} \mathrm{M}\right)$, trifluoperazine $\left(10^{-4} \mathrm{M}\right)$, or acetazolamide $\left(10^{-3} \mathrm{M}\right)$ (data not shown). We observed a small decrease $(20-30 \%)$ in the presence of iodoacetate $\left(10^{-2} \mathrm{M}\right)$ or $\mathrm{KCN}\left(10^{-3} \mathrm{M}\right)$. The decrease in the apical-to-basal flux was gradual, in spite of the rapid drop in transepithelial potential upon addition of $\mathrm{KCN}$.

The apical-to-basal flux could be inhibited to the level of the basal-to-apical flux by first exposing the tissue to solution containing no glucose and then to $10^{-3} \mathrm{M} \mathrm{KCN}$. While zero glucose itself had little effect on the fluxes, the rapidity of the effect of $\mathrm{KCN}$ depended on the length of exposure of the tissue to zero glucose (Fig. 4). For example, in Figure $4 A, \mathrm{KCN}$ was added with the zero glucose solution. Approximately $2 \mathrm{hr}$ were required for the fluxes in the 2 directions to become equal. In Figure $4 C$ the tissuc was cxposcd to zcro glucose for $2 \mathrm{hr}$, and there was no change in the flux during that time. Upon addition of $\mathrm{KCN}$, there was an immediate drop in the apical-to-basal flux and a maximum decrease occurred within $30 \mathrm{~min}$.

Exposure of the tissue to a transepithelial concentration gradient produced evidence for a countertransport system. When the apical side of the tissue was exposed to $11 \mu \mathrm{M}$ leucine and the basal side to $250 \mu \mathrm{M}$ leucine, a net flux in the basal-to-apical direction was observed (Table 3 ). In addition, the apical-tobasal flux with $250 \mu \mathrm{M}$ leucine on the basal side was greater than the apical-to-basal flux with $11 \mu \mathrm{M}$ leucine on the basal side, despite the fact that $11 \mu \mathrm{M}$ leucine was on the apical side in both cases (Table 3 ). This suggests the presence of a countertransport or exchange diffusion system at either the apical membrane, sensitive to the intracellular concentration, or at the ba- 


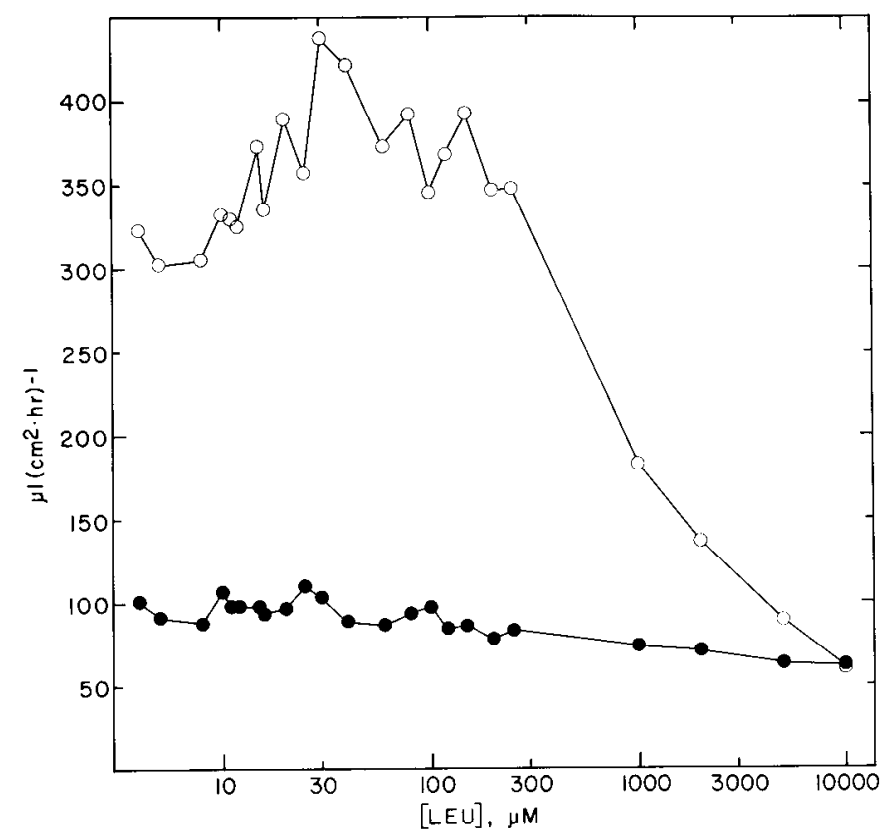

Figure 3. Unidirectional clearance values for leucine as a function of leucine concentration. Values were obtained by dividing the data from Figure 2 by the concentration of leucine, and expressed as microliters $(\mu \mathrm{l}) / \mathrm{cm}^{2} / \mathrm{hr}$. Open circles, Apical-to-basal clearance; filled circles, basalto-apical clearance.

solateral membrane, sensitive to the concentration on the basal side. No such effect on the basal-to-apical flux was found, i.e., the $11 \mu \mathrm{M}$ apical $/ 250 \mu \mathrm{M}$ basal gradient across the tissue did not change the flux from that observed with $250 \mu \mathrm{M}$ leucine on both sides (Table 3).

While a net flux of solute in the apical-to-basal direction is characteristic of an absorptive epithelium, few of the other results were so consistent. Therefore, we needed to establish exhaustively that the net apical-to-basal flux was not an artifact. The following arguments can be made for the validity of the net flux: (1) There is no net flux of leucine when the nylon mesh alone is used (i.e., no tissue), and the net apical-to-basal flux retains its proper direction when the orientation of the tissue between the plates is reversed. Therefore, the net flux was not due to some characteristic of the plates or compartments of the chamber. (2) In some experiments, the RPE was stripped from the choroid either by scraping with a glass pipette, by brief exposure to distilled water, or by dissecting the tissue from a light-adapted frog in white light. Measuring the fluxes across the isolated choroid demonstrated that the apical-to-basal flux was lower and the basal-to-apical flux higher than when the tissue was intact. Thus the RPE was responsible for modifying the movement of substrate, and for the usual fluxes that we ob-

Table 2. Unidirectional clearances of $\mathrm{D}$ - and L-leucine
\begin{tabular}{lll} 
Apical $\rightarrow$ & $\begin{array}{l}\text { Basal } \rightarrow \\
\text { basal }\end{array}$ & $\begin{array}{l}\text { apical } \\
\text { Substrate }(\mu \mathrm{M})\end{array}$ \\
\hline 250 L-leu & 330.4 & 63.0 \\
250 L-leu & 209.6 & 79.7 \\
250 L-leu + 100 D-leu & 307.1 & 76.5 \\
250 L-leu +250 D-leu & 353.0 & 74.5 \\
250 D-leu & 170.4 & 80.1 \\
250 D-leu & 237.6 & 69.2
\end{tabular}

Clearances are in microliters $(\mu \mathrm{l}) / \mathrm{cm}^{2} / \mathrm{hr}$; data are from individual experiments.

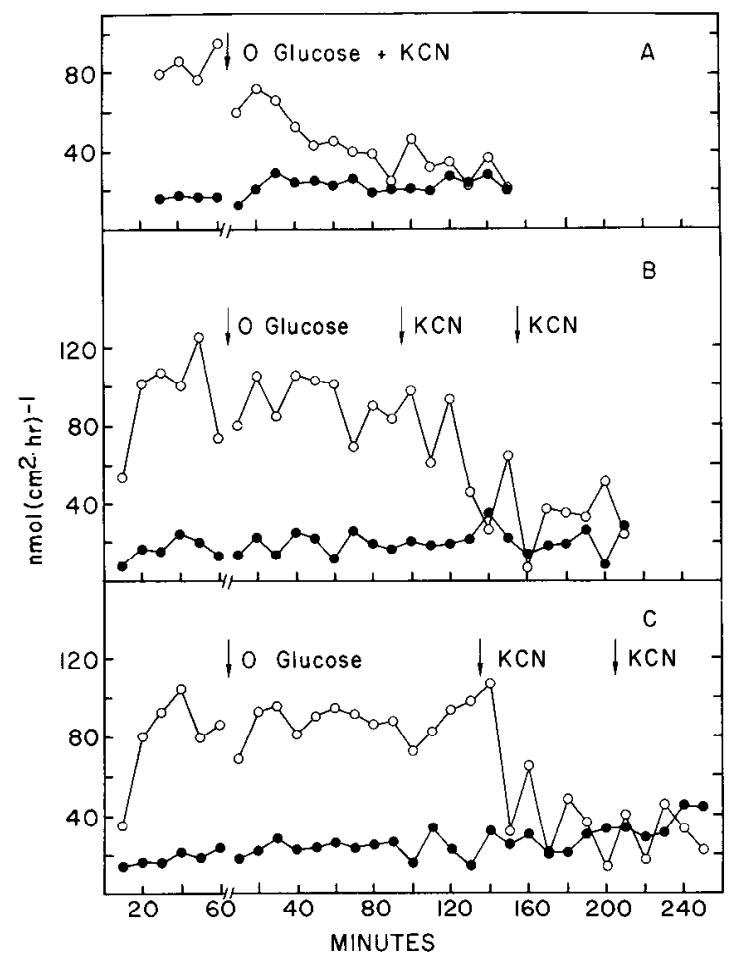

Figure 4. Unidirectional fluxes of leucine $(250 \mu \mathrm{M})$ in the absence of glucose $(0$ Glucose) and presence of $K C N$. Fluxes were measured in control solution for $60 \mathrm{~min}$, then the solutions on both sides were replaced with solution without glucose. At the time(s) indicated, KCN was added to both sides to a final concentration of $10^{-3} \mathrm{M}$. Open circles, Apical-to-basal flux; filled circles, basal-to-apical flux. Data are from individual experiments.

served. (3) No net flux of the extracellular markers inulin and mannitol was detected, as was indicated previously. Furthermore, those fluxes were quite small, consistent with the absence of a significant leak in the preparation. (4) The magnitude of the net flux across the RPE-choroid was dependent upon the particular substrate, i.e., the value of apical-to-basal/basal-toapical flux varied from 1 (glucose) to 8 (tyrosine) (Sellner, in press).

In summary, the apical-to-basal flux was somewhat sensitive to the loss of the $\mathrm{Na}^{+}$gradient and to some of the metabolic inhibitors. The flux was only substantially inhibited, however, when the tissue was incubated with 0 glucose for $1-2 \mathrm{hr}$ and then exposed to $\mathrm{KCN}$. The apical-to-basal flux, which is not stereospecific, possesses 3 components: a small countertransport system, a large-capacity saturable carrier, and a linear compo-

\section{Table 3. Unidirectional fluxes for leucine with and without a} transepithelial concentration gradient

\begin{tabular}{cccc}
$\begin{array}{l}C_{\mathrm{A}} \\
(\mu \mathrm{M})\end{array}$ & $\begin{array}{l}C_{\mathrm{B}} \\
(\mu \mathrm{M})\end{array}$ & $\begin{array}{l}\text { Apical } \rightarrow \text { basal } \\
\mathrm{nmol} / \mathrm{cm}^{2} / \mathrm{hr}\end{array}$ & $\begin{array}{l}\text { Basal } \rightarrow \text { apical } \\
\mathrm{nmol} / \mathrm{cm}^{2} / \mathrm{hr}\end{array}$ \\
\hline 11 & 11 & $3.38 \pm 0.77$ & $1.08 \pm 0.29$ \\
& & $(9)$ & $(9)$ \\
250 & 250 & $88.7+21.2$ & $18.86 \pm 3.29$ \\
& & $(10)$ & $(10)$ \\
11 & 250 & $5.38 \pm 0.72$ & $17.02 \pm 2.49$ \\
& & $(9)$ & $(10)$
\end{tabular}

Fluxes were measured with the indicated concentration of leucine on the apical $\left(C_{\mathrm{A}}\right)$ and basal $\left(C_{\mathrm{B}}\right)$ sides of the tissue. Data are expressed as means $\pm \mathrm{SD}$ for the number of experiments given in parentheses. 
nent. The clearance in this direction is sensitive to extracellular substrate concentrations, while that in the basal-to-apical direction is not. The basal-to-apical flux was not inhibited by any of the experimental manipulations, and, in fact, showed a slight (but not significant) stimulation in some cases. The flux is also not stereospecific, and is linear with substrate concentration.

\section{Discussion}

The typical systems for the transport of neutral amino acids were initially described for Ehrlich cells by Oxender and Christensen (1963). The A system, named for its preference for alanine, transports smaller substrates and is $\mathrm{Na}^{+}$-dependent, while the $\mathrm{L}$ system prefers larger substrates, such as leucine, and is $\mathrm{Na}^{+}$-independent. In cerebral microvessels (Cangiano et al., 1983) and rabbit intestinal epithelium (Stevens et al., 1982), both A and $\mathrm{L}$ systems and others appear to be present. A similarly complex system for leucine transport across the RPE-choroid must also exist, as the major portion of the apical-to-basal flux was insensitive to the loss of the $\mathrm{Na}^{+}$gradient or to the presence of various poisons. This flux could be $75 \%$ inhibited with $\mathrm{KCN}$ and 0 glucose in the solution and was partly saturable. The basalto-apical flux was completely insensitive to any of these treatments and did not begin to saturate even at concentrations as high as $10 \mathrm{~mm}$.

The concentration dependence of the fluxes is very similar to the result described for methionine transport across the RPE by Miller and Steinberg (1976). These authors observed that the apical-to-basal flux began to saturate at between 10 and $30 \mu \mathrm{M}$, while the basal-to-apical flux was linear throughout the concentration range. In addition, the difference between the 2 fluxes decreased as the concentration increased, with the fluxes equal at $30 \mathrm{~mm}$ methionine. The apical-to-basal flux was slowly affected by ouabain, while the basal-to-apical flux was completely unaffected.

The apical-to-basal flux data were fitted to a model that assumes 2 components, a saturable Michaelis-Menten type of carrier and a linear mechanism. The $K_{\mathrm{m}}$ and $V_{\max }$ values obtained for the carrier are similar to those reported for taurine transport across the RPE (Miller and Steinberg, 1976). It is curious, however, that the $K_{\mathrm{m}}$ for these amino acid transport systems is in the millimolar range, given the low levels of leucine surrounding the tissue. Blood levels of leucine, for example, are $0.1 \mathrm{~mm}$ in the bullfrog (Just and Robinson, 1977), and the concentration of leucine in subretinal fluid has been estimated at $10 \mu \mathrm{M}$ (Sellner, in press). Neither the carrier nor the linear component would thus appear to provide much regulation of subretinal fluid levels or of the transepithelial gradient. In fact, while the computer fit is sufficient to explain the kinetic data at higher concentrations (>40 $\mu \mathrm{M}$ ), there is a problem at the low (i.c., physiological) range (Fig. 2). The observed flux is consistently lower than would be predicted from the sum of the saturable and linear systems. The discrepancy can be explained by a mechanism with cooperative binding, such as countertransport. This component appcars to be a small contribution in absolute terms, but it is significant at low concentrations. There are thus 3 systems involved in the apical-to-basal flux.

If we assume that the saturable component of the apical-tobasal flux is also $\mathrm{Na}^{+}$-dependent, there are still at least 3 possibilities for the linear portion. One is a carrier with low affinity and high capacity that is independent of the sodium gradient, as described by Paterson et al. (1980) for rabbit ileal mucosa. As this is not saturable under these experimental conditions, this system is indistinguishable from the second possibility, free diffusion. The latter mechanism and the third, pinocytosis, also have a number of features in common: movement of solute is linear with concentration, does not saturate, and need not be stereospecific or immediately energy-dependent. One necessary requirement for either mechanism is that it be sensitive to the transepithelial gradient, as in Figure 3, such that the apical-tobasal movement of substrate can be adjusted.

While we cannot rule out diffusion as a partial explanation for the equal and opposite fluxes remaining in the presence of $\mathrm{KCN}$ and 0 glucose, we can infer that another mechanism is present. Rates of diffusion in the basal-to-apical and apical-tobasal directions must be equal. However, the fluxes are equal at $10 \mathrm{~mm}$ leucine (Fig. 4), and since it seems clear that the apicalto-basal flux contains a carrier-mediated component, only a fraction of that flux can be diffusion. Therefore, some of the basal-to-apical flux must also be nondiffusing. Similarly, the linear component of the apical-to-basal flux is smaller than the slope of the basal-to-apical flux, which suggests that part of the latter flux occurs via a mechanism other than diffusion, such as pinocytosis.

There is evidence for pinocytosis in both the choroid plexus and the RPE. Van Deurs (1976, 1977) and Brightman (1967) concluded that pinocytosis in the choroid plexus occurs in the apical-to-basal direction and may occur in the opposite direction as well. Micropinocytic vesicles have been described in mouse RPE as a function of age (Kondo, 1979), and Orzalesi et al. (1982) have described coated vesicles at the apical and basolateral borders. These "coats" typically imply a receptor-mediated uptake, but may also serve as a mechanism of generalized transport, particularly of fluid. Miller and coworkers have pointed out the importance of fluid transport by the RPE in normal and pathologic conditions (Hughes et al., 1984; Miller and Farber, 1984).

The movement of a pinocytic vesicle across the epithelial cell raises an interesting point with respect to the mannitol and leucine fluxes reported in Table 1. If the path for such a vesicle were straight through the cell (i.e., in at the basolateral border, translocation to the apical membrane, then exocytosis), then the fluxes of the 2 substrates would be identical, which they are not (Table 1). In addition, we know that the apical and basolateral membranes have different compositions and therefore must remain segregated. For instance, the apical membrane contains a $\mathrm{Na}^{+}-\mathrm{K}^{+}$-ATPase while the basolateral membrane does not (Ostwald and Steinberg, 1980). Also, the latter possesses a receptor for serum retinol-binding protein, which the apical membrane does not have (Bok and Heller, 1976). Thus, there must be some fusion of the pinocytic vesicle with an intracellular lysosome and sorting out of the membrane material so it can be accurately recycled.

\section{References}

Altman, P. L., and D. S. Dittmer (1974) "Blood non-protein nitrogenous substances: Man" and "Physical properties and chemical composition of cerebrospinal fluid: Mammals." In Biology Data Book, 2nd Ed., Vol. III, P. L. Altman and D. S. Dittmer, eds., pp. 18061807, 1976-1977, Federation of American Societies for Experimental Biology, Bethesda, MD.

Bok, D. (1982) Autoradiographic studies on the polarity of plasma membrane receptors in retinal pigment epithelial cells. In The Structure of the Eye, J. G. Hollyfield, ed., pp. 247-256, Elsevier-North Holland, New York.

Bok, D., and J. Heller (1976) Transport of retinol from the blood to the retina: An autoradiographic study of the pigment epithelial cell surface receptor for plasma retinol-binding protein. Exp. Eye Res. 22 : 395-402.

Brightman, M. W. (1967) The intracerebral movement of proteins injected into blood and cerebrospinal fluid of mice. Prog. Brain Res. 29: 19-37.

Cangiano, C., P. Cardelli-Cangiano, J. H. James, F. Rossi-Fanelli, M. A. Patrizi, K. A. Brackett, R. Strom, and J. E. Fischer (1983) Brain microvessels take up large neutral amino acids in exchange for glutamine. Cooperative role of $\mathrm{Na}^{+}$-dependent and $\mathrm{Na}^{+}$-independent systems. J. Biol. Chem. 258: 8949-8954.

Hughes, B. A., S. S. Miller, and T. E. Machen (1984) Effects of cyclic 
AMP on fluid absorption and ion transport across frog retinal pigment epithelium. J. Gen. Physiol. 83: 875-899.

Just, J. J., and G. W. Robinson (1977) Plasma amino acid levels during metamorphosis of the bull frog Rana catesbeiana. Comp. Biochem. Physiol. 58: 133-136.

Kondo, K. (1979) Ultrastructural observations of age changes in the mouse retinal pigment epithelium. II. Analysis of micropinocytotic vesicles at the basal infoldings. Acta Soc. Ophthalmol. Jpn. 83: 22362250 .

Lasansky, A., and F. W. deFisch (1966) Potential, current, and ionic fluxes across the isolated retinal pigment epithelium and choroid. $J$. Gen. Physiol. 49: 913-924.

Lorenzo, A. V. (1974) Amino acid transport mechanisms of the cerebrospinal fluid. Fed. Proc. 33: 2079-2085.

Miller, S., and D. Farber (1984) Cyclic AMP modulation of ion transport across frog retinal pigment epithelium. J. Gen. Physiol. 83: 853874

Miller, S., and R. H. Steinberg (1976) Transport of taurine, L-methionine, and 3-o-methyl-D-glucose across frog retinal pigment epithelium. Exp. Eye Res. 23: 177-189.

Miller, S. S., and R. H. Steinberg (1977) Passive ionic properties of frog retinal pigment epithelium. J. Membrane Biol. 36: 337-372.
Orzalesi, N., M. Fossarello, S. Carla, G. Del Fiacco, and G. Diaz (1982) Identification and distribution of coated vesicles in the retinal pigment epithelium of man and rabbit. Invest. Ophthalmol. Vis. Sci. 23: 689696.

Ostwald, T. J., and R. H. Steinberg (1980) Localization of frog retinal pigment epithelium $\mathrm{Na}^{+}-\mathrm{K}^{+}$ATPase. Exp. Eye Res. 31: 351-360.

Oxender, D. L., and H. N. Christensen (1963) Distinct mediating systems for the transport of neutral amino acids by the Ehrlich cell. J. Biol. Chem. 238: 3686-3699.

Paterson, J. Y. F., F. V. Sepulveda, and M. W. Smith (1980) A sodiumindependent low affinity transport system for neutral amino acids in rabbit ileal mucosa. J. Physiol. (Lond.) 298: 333-346.

Sellner, P. A. (1986) The movement of organic solutes between the retina and pigment epithelium. Exp. Eye Res. (in press).

Stevens, B. R., H. J. Ross, and E. M. Wright (1982) Multiple transport pathways for neutral amino acids in rabbit jejunal brush border vesicles. J. Membr. Biol. 66: 213-225.

Van Deurs, B. (1976) Choroid plexus absorption of horseradish peroxidase from the cerebral ventricles. J. Ultrastruct. Res. 55: 400-416.

Van Deurs, B. (1977) Vesicular transport of horseradish peroxidase from brain to blood in segments of the cerebral microvasculature in adult mice. Brain Res. 124: 1-8. 